\title{
Factors Affecting the Downward Mobility of Psychiatric Patients: A Korean Study of National Health Insurance Beneficiaries
}

\author{
Un-Na Kim ${ }^{1}$, Yeon-Yong Kim ${ }^{1}$, Jin-Seok Lee ${ }^{1,2}$ \\ ${ }^{1}$ Department of Health Policy and Management, Seoul National University College of Medicine, Seoul; ${ }^{2}$ Institute of Health Policy and Management, \\ Seoul National University Medical Research Center, Seoul, Korea
}

Objectives: The purpose of this study is to examine the magnitude of and the factors associated with the downward mobility of firstepisode psychiatric patients.

Methods: This study used the claims data from the Korean Health Insurance Review and Assessment Service. The study population included 19293 first-episode psychiatric inpatients diagnosed with alcohol use disorder (International Classification of Diseases, 10th revision [ICD-10] code F10), schizophrenia and related disorders (ICD-10 codes F20-F29), and mood disorders (ICD-10 codes F30-F33) in the first half of 2005. This study included only National Health Insurance beneficiaries in 2005. The dependent variable was the occurrence of downward mobility, which was defined as a health insurance status change from National Health Insurance to Medical Aid. Logistic regression analysis was used to assess factors associated with downward drift of first-episode psychiatric patients.

Results: About 10\% of the study population who were National Health Insurance beneficiaries in 2005 became Medical Aid recipients in 2007. The logistic regression analysis showed that age, gender, primary diagnosis, type of hospital at first admission, regular use of outpatient clinic, and long-term hospitalization are significant predictors in determining downward drift in newly diagnosed psychiatric patients.

Conclusions: This research showed that the downward mobility of psychiatric patients is affected by long-term hospitalization and medical care utilization. The findings suggest that early intensive intervention might reduce long-term hospitalization and the downward mobility of psychiatric patients.

Key words: Social mobility, Mental disorders, National Health Insurance, Republic of Korea

Received: August 27, 2015 Accepted: December 22, 2015

Corresponding author: Jin-Seok Lee, MD, PhD

103 Daehak-ro, Jongno-gu, Seoul 03080, Korea

Tel: +82-2-740-8362, Fax: +82-2-743-2009

E-mail: phealth@snu.ac.kr

This is an Open Access article distributed under the terms of the Creative Commons Attribution Non-Commercial License (http://creativecommons.org/licenses/by$\mathrm{nc} / 3.0 /$ ) which permits unrestricted non-commercial use, distribution, and reproduction in any medium, provided the original work is properly cited.

\section{INTRODUCTION}

The importance of mental disorders is being emphasized globally. According to the results of the Global Burden of Disease Study, the burden of mental disorders accounted for $7.4 \%$ of the overall disease burden [1], and the burden of major depressive disorder is estimated to be the largest among single diseases in 2030 [2]. In Korea, the lifetime prevalence rate of psychiatric disorder was $27.6 \%$, according to the Epidemiolog- 
ical Survey of Mental Disorders in 2011 [3].

Although the fatality rate of psychiatric disorder is not high, psychiatric disorder may cause physically and socially serious disabilities [4]. Early detection and intensive intervention of psychiatric disorder may prevent its chronicization and accelerate patients' social rehabilitation [5]. However, many psychiatric patients do not receive appropriate treatment services at an early stage and experience difficulties in social activities, such as employment [6]. The labor force participation rate of psychiatric patients is very low compared with that of the general population $[7,8]$. Due to such a low labor force participation rate and the burden of medical expenses, psychiatric patients are known to have a high likelihood of poverty $[6,9,10]$.

Over the last few decades, studies examining the relationship between psychiatric disorder and socioeconomic status have been conducted $[11,12]$. In general, psychiatric disorder is known to occur more in those with a low socioeconomic status $[10,13,14]$. Such a relationship between psychiatric disease and socioeconomic status can be explained by social causation theory and social selection and drift theory $[15,16]$. First, the social causation theory states that people with a low socioeconomic status may have a greater risk for psychiatric disorder because of economic and social stress. Second, the social selection and drift theories state that psychiatric patients may be faced with a lower social-economic status after the onset of psychiatric disorder, and the two theories are similarly used [16]. The correlation between socioeconomic status and psychiatric disorder has been reported in Korea as well. The National Basic Livelihood Security recipient and unemployment rates of persons with psychiatric disorder were high among those with disabilities [17]. Considering the high unemployment and poverty rates of psychiatric patients in Korea, it seems reasonable to focus more on the social drift theory, which states that socioeconomic status may decline after the onset of psychiatric disorder.

Most previous foreign studies on mobility of psychiatric patients analyzed employment status changes. Factors affecting the social mobility of psychiatric patients included education level, length of hospitalization, severity of symptoms, history of occupation, age of onset, and negative symptoms [18-23]. Despite the downward mobility of psychiatric patients posing a serious issue, there are few domestic studies on the mobility of psychiatric patients [24]. One study exists on the poverty status change of those with mental disabilities [24], and studies analyzing income mobility and poverty status changes of the disabled households, including psychiatric patients, have also been conducted $[25,26]$. In addition, follow-up studies exist on the occupational mobility of people with psychiatric disabilities regarding relationships between psychiatric disorder and socioeconomic status $[8,27,28]$. In the findings of previous studies in Korea, factors affecting the mobility of people with psychiatric disabilities included education level, number of household members, employment experience, and amount of public assistance benefits $[8,24,27,28]$. However, previous studies on employment status changes did not reflect the direct economic level and the downward mobility of psychiatric patients after the onset of psychiatric disorder using representative data. In order to prevent the chronicization of psychiatric disorder and poverty, an examination of the downward mobility of first-episode psychiatric patients and exploration of the factors associated with the downward mobility are necessary.

The purpose of this study is to examine the downward mobility using a 3-year follow-up study with all inpatients who had first-episode psychiatric disorder in 2005 and analyze the factors associated with the downward mobility of psychiatric patients.

\section{METHODS}

\section{Participants}

This study used claims data for psychiatric disorders from the Korean Health Insurance Review and Assessment Service (HIRA) between 2003 and 2007. Participants were National Health Insurance (NHI) beneficiaries who were first diagnosed with mental and behavioral disorders due to use of alcohol (International Classification of Diseases, 10th revision [ICD-10] code F10), schizophrenia, schizotypal and delusional disorders (ICD-10 codes F20-F29), and mood disorders (ICD-10 codes F30-F39) from January to June 2005 and who were hospitalized. Patients who had a history of hospitalization or outpatient care claims for the codes of study from 2003 to 2004 were not considered first-episode patients and were excluded. Alcohol use disorder is not included in the psychiatric disabilities according to the Disabled Welfare Act; however, because alcohol use disorder has the highest life prevalence with $13.4 \%$ among single psychiatric disorders [3] and is a socially serious problem [29], it was included in this study. This study was conducted using the study findings on relationships between treatment patterns of first-episode psychiatric patients and long-term hospitalization of Suh et al. [30], and was ap- 
proved by the institutional review board at the Seoul National University Hospital.

\section{Definition of Variables}

The patients' health insurance status change was used as a dependent variable. Health insurance status was classified into $\mathrm{NHI}$ and Medical Aid; the latter included type 1 Medical Aid, type 2 Medical Aid, and unknown or unidentified. Downward mobility was defined as the health insurance status change from NHI to Medical Aid. The explanatory variables which are available in the HIRA claim data include gender, age, primary diagnosis, type of hospital at the first admission, regular use of outpatient clinic, experience of long-term hospitalization, total medical expenses, and number of hospital visits.

The primary diagnosis was divided into alcohol use disorder (F10), schizophrenia-related disorder (F20-F29), and mood disorder (F30-F39). In order to examine the effects of early effective intervention at the onset of psychiatric disorder on the downward mobility, the type of hospital at patient's first admission and regular use of outpatient care were used as variables. Because the health insurance claims data did not contain the details of medical service utilization, the quality of treatment could not be verified. In this regard, the type of hospital at the first admission was used as a surrogate indicator that reflects early intensive hospitalization treatment at the onset of psychiatric disorder by referring to a study by Suh et al. [30]. It was assumed that there would be differences in the quality of hospitalization treatment depending on the type of hospital and tertiary hospitals and general hospitals would provide intensive treatment. The type of hospital at the first admission was divided into tertiary hospitals, general hospitals, hospitals, and clinics. Regular use of the outpatient clinic was defined as the interval between outpatient visits being less than 60 days if related outpatient care was used for the corresponding diseases from 2005 to 2007.

In order to examine the mobility of psychiatric patients by their medical care utilization, medical care utilization was redefined. The patient group was divided into eight groups based on the type of hospital at the first admission and regular use of outpatient care. Group A: patients first admitted to a tertiary hospital with subsequently regular outpatient visits, group B: patients admitted to a tertiary hospital with irregular outpatient visits, group C: patients admitted to a general hospital with regular outpatient visits, group D: patients admitted to a general hospital with irregular outpatient visits, group $\mathrm{E}$ : patients admitted to a hospital with regular outpatient visits, group F: patients admitted to a hospital with irregular outpatient visits, group G: patients admitted to a clinic with regular outpatient visits, and group $\mathrm{H}$ : patients admitted to a clinic with irregular outpatient visits.

Long-term hospitalization was defined as being hospitalized for 180 days or more by reference to previous studies [3032]. If the period between discharge from a hospital and readmission was within 30 days, it was treated as a continued hospitalization.

\section{Statistical Analysis}

The general participant characteristics were analyzed using a frequency analysis. Chi-square test and $t$-test were used to compare the factors that could affect downward mobility. To examine the factors affecting the downward mobility of the first-episode psychiatric patients, a logistic regression analysis was performed using gender, age, primary diagnosis, type of hospital at the first admission, regular outpatient visit, and total medical expense as variables. SAS version 9.4 (SAS Institute Inc., Cary, NC, USA) was used as a statistical program and the statistical significance was set to 0.05 .

\section{RESULTS}

The general characteristics of the 19293 participants are as follows (Table 1). Men comprised $55.0 \%$ while those aged 40 to 49 years were the most frequent $(25.0 \%)$. For primary diagnosis, mood disorder was the most common, accounting for $36.1 \%$. For the type of hospital at first admission, hospital accounted for $46.3 \%$. Out of all participants, $27.0 \%$ had used regularly outpatient clinic, and $11.0 \%$ had a long-term hospitalization experience.

Between 2005 and 2007, 10.7\% of all participants experienced downward mobility. The results of the chi-square test and $t$-test for each variable and downward mobility experience are as follows (Table 1). Downward mobility occurred more in men and in those aged 30 to 39 years and 40 to 49 years. Downward mobility occurred in $14.4 \%$ of patients with alcohol use and in $15.8 \%$ of patients who were admitted to a hospital at the first admission. Downward mobility occurred more in patients with irregular use of outpatient clinic and long-term hospitalization experience. Average number of days in hospital was 375 in patients with downward mobility, which was higher compared to patients without downward mobility. All vari- 
Table 1. General characteristics of the study population and univariate analysis by health insurance status change

\begin{tabular}{|c|c|c|c|}
\hline \multirow{2}{*}{ Variables } & \multirow{2}{*}{ Total } & \multicolumn{2}{|c|}{ Health insurance status change } \\
\hline & & Downward mobility (+) & Downward mobility (-) \\
\hline Total & $19293(100)$ & $2057(10.7)$ & 17236 (89.3) \\
\hline \multicolumn{4}{|l|}{ Gender*** } \\
\hline Men & $10602(55.0)$ & $1438(13.6)$ & $9164(86.4)$ \\
\hline Women & $8691(45.0)$ & $619(7.1)$ & $8072(92.9)$ \\
\hline \multicolumn{4}{|l|}{ Age (y) } \\
\hline$\leq 19$ & $685(3.6)$ & $29(4.2)$ & $656(95.8)$ \\
\hline $20-29$ & $2610(13.5)$ & $217(8.3)$ & $2393(91.7)$ \\
\hline $30-39$ & $4350(22.5)$ & $707(16.3)$ & $3643(83.7)$ \\
\hline $40-49$ & $4818(25.0)$ & $779(16.2)$ & 4039 (83.8) \\
\hline $50-59$ & $3135(16.2)$ & $226(7.2)$ & 2909 (92.8) \\
\hline$\geq 60$ & $3695(19.2)$ & $99(2.7)$ & $3596(97.3)$ \\
\hline \multicolumn{4}{|l|}{ Primary diagnosis (ICD-10)*** } \\
\hline F10 & $5886(30.5)$ & $850(14.4)$ & $5036(85.6)$ \\
\hline F20-F29 & $6440(33.4)$ & $921(14.3)$ & $5519(85.7)$ \\
\hline F30-F33 & $6967(36.1)$ & $286(4.1)$ & 6681 (95.9) \\
\hline \multicolumn{4}{|l|}{ Type of hospital (first admission) } \\
\hline Tertiary hospital & $3658(19.0)$ & $101(2.8)$ & $3557(97.2)$ \\
\hline General hospital & 4425 (22.9) & $301(6.8)$ & 4124 (93.2) \\
\hline Hospital & $8925(46.3)$ & $1413(15.8)$ & 7512 (84.2) \\
\hline Clinic & $2285(11.8)$ & $242(10.6)$ & $2043(89.4)$ \\
\hline \multicolumn{4}{|l|}{ Regular use (outpatient) } \\
\hline Yes & $5216(27.0)$ & $417(8.0)$ & $4799(92.0)$ \\
\hline No & $14077(73.0)$ & $1640(11.7)$ & 12437 (88.3) \\
\hline \multicolumn{4}{|l|}{ Long-term hospitalization ${ }^{* * *}$} \\
\hline Yes & $2125(11.0)$ & $943(44.4)$ & $1182(55.6)$ \\
\hline No & $17168(89.0)$ & $1114(6.5)$ & 16054 (93.5) \\
\hline Medical expenditure $(3 y)^{* * *}$ & $5348772 \pm 8170854$ & $12161584 \pm 9481682$ & $4535709 \pm 7603006$ \\
\hline Length of hospitalization $(\mathrm{d})^{* * *}$ & $116 \pm 196.9$ & $375 \pm 304.0$ & $85.1 \pm 152.9$ \\
\hline
\end{tabular}

Values are presented as number (\%) or mean \pm standard deviation.

ICD-10, International Classification of Diseases, 10th revision; F10, alcohol use disorder; F20-F29, schizophrenia and related disorders; F30-F33, mood disorders. ${ }^{* * *} p<0.001$.

ables were statistically significant in univariate analysis.

A logistic regression analysis was performed using gender, age, primary diagnosis, pattern of medical care utilization, long-term hospitalization experience, and total medical expense as explanatory variables (Table 2). Days of hospital visits were excluded from the logistic regression analysis due to the multicollinearity between the long-term hospitalization experience and total medical expenses. Women were at a lower risk of downward mobility compared to men. The risk of downward mobility in those aged 30 to 39 was 2.58 times higher compared to those aged under 19 . Regarding primary diagnosis, the risk of downward mobility was lower in those with mood disorder compared to those with alcohol use disorder. The risk of downward mobility in patients with long-term hospitalization experience was 8.69 times higher compared to those without such experience. The difference in downward mobility according to total medical expenses was not statistically significant.

Regarding the pattern of medical care utilization, the risk of downward mobility was 2.24 times higher in group B (those admitted to a tertiary hospital with subsequently irregular outpatient clinic visits) compared to group A (those admitted to a tertiary hospital with regular outpatient visits). The risk of downward mobility was 6.65 times higher in group F (those admitted to a hospital with subsequently irregular outpatient care), which was the highest among the eight groups. 
Table 2. Determinants of downward mobility in those newly diagnosed with a mental disorder

\begin{tabular}{|c|c|c|}
\hline Variables & $\mathrm{OR}^{1}(95 \% \mathrm{CI})$ & $p$-value \\
\hline \multicolumn{3}{|l|}{ Gender } \\
\hline Men & 1.00 (reference) & \\
\hline Women & $0.75(0.66,0.84)$ & $<0.001$ \\
\hline \multicolumn{3}{|l|}{ Age (y) } \\
\hline$\leq 19$ & 1.00 (reference) & \\
\hline $20-29$ & $1.47(0.97,2.24)$ & 0.07 \\
\hline $30-39$ & $2.58(1.73,3.87)$ & $<0.001$ \\
\hline $40-49$ & $2.49(1.66,3.74)$ & $<0.001$ \\
\hline $50-59$ & $0.87(0.57,1.33)$ & 0.53 \\
\hline$\geq 60$ & $0.31(0.20,0.48)$ & $<0.001$ \\
\hline \multicolumn{3}{|l|}{ Primary diagnosis (ICD-10) } \\
\hline F10 & 1.00 (reference) & \\
\hline F20-F29 & $0.97(0.85,1.10)$ & 0.64 \\
\hline F30-F33 & $0.52(0.44,0.61)$ & $<0.001$ \\
\hline \multicolumn{3}{|c|}{ Medical care utilization group } \\
\hline A & 1.00 (reference) & \\
\hline$B$ & $2.24(1.26,3.98)$ & 0.006 \\
\hline C & $2.71(1.48,4.97)$ & 0.001 \\
\hline D & $5.13(2.96,8.89)$ & $<0.001$ \\
\hline$E$ & $4.84(2.79,8.41)$ & $<0.001$ \\
\hline $\mathrm{F}$ & $6.65(3.88,11.41)$ & $<0.001$ \\
\hline G & $3.38(1.82,6.30)$ & $<0.001$ \\
\hline $\mathrm{H}$ & $4.94(2.82,8.64)$ & $<0.001$ \\
\hline \multicolumn{3}{|l|}{ Long-term hospitalization } \\
\hline Yes & $8.69(7.33,10.31)$ & $<0.001$ \\
\hline No & 1.00 (reference) & \\
\hline Medical expenditure (3 y) & $1.00(1.00,1.00)$ & 0.38 \\
\hline
\end{tabular}

$\mathrm{OR}$, odds ratio; $\mathrm{Cl}$, confidence interval; ICD-10, International Classification of Diseases, 10th revision; F10, alcohol use disorder; F20-F29, schizophrenia and related disorders; F30-F33, mood disorders; A, tertiary hospital admission and regular outpatient clinic access; $B$, tertiary hospital admission and irregular outpatient clinic access; $C$, general hospital admission and regular outpatient clinic access; D, general hospital admission and irregular outpatient clinic access; E, hospital admission and regular outpatient clinic access; F, hospital admission and irregular outpatient clinic access; $G$, clinic admission and regular outpatient clinic access; $\mathrm{H}$, clinic admission and irregular outpatient clinic access.

${ }^{1}$ Adjusted for all other variables in the table.

\section{DISCUSSION}

In this study, we analyzed the health insurance status change and factors affecting the change in the whole $\mathrm{NHI}$ beneficiaries who were first diagnosed with a psychiatric disorder in the first half of 2005, using the claims data from the Korean HIRA. The present study findings showed that $10.7 \%$ of psychiatric patients who were the $\mathrm{NHI}$ beneficiaries at the first admission drifted downward to Medical Aid recipients. Gender, age, primary diagnosis, type of medical care utilization, and long-term hospitalization were found to affect the downward mobility of first-episode psychiatric patients.

In previous studies, poverty status change, or employment status change, was operationally defined as mobility. This study is significant in that it used health insurance status as the hierarchical status verified by official government standards.

No previous study on the health insurance status change of psychiatric patients exists, but studies on the mobility of those with mental disabilities and physical disabilities have been conducted. In a study by Lee [24], which analyzed the poverty rate of households comprising those with a mental disability using Korea Welfare Panel data, the poverty rate of such households increased from $25.0 \%$ in the first year to $39.5 \%$ in the 7 th year. Although it was not limited to those with mental disabilities, the rate of entering the poverty status became higher after the onset of disability [33]. The follow-up study with the income of people at the onset of disability showed that $68 \%$ had a decline in income 10 years after the onset of disability [34]. In addition, in the 10-year follow-up study for the occupational mobility of schizophrenia patients, $6.8 \%$ of patients changed their occupational status from a higher level to a lower level [16]. Psychiatric patients are likely to be at a disadvantage for employment due to social discrimination and stigma against psychiatric patients and, thus, are more likely to fall in poverty, which may lead to the persistence of poverty over time [6,9].

Downward mobility was more common in men compared to women. These findings are consistent with the results of previous studies [18]. As, in general, the labor force participation rate of men is higher than that of women, and women are more affected by their spouse's health insurance status, men are considered to be at a higher risk of downward mobility than women.

By age, those in their 30s and 40s have a high risk for downward mobility, apparently because those in their 30s and 40s who belong to economically productive age group are forced out of the labor market or their employment status becomes deteriorated. In contrast, those aged over 60 years with a low labor force participation rate had a relatively low risk for downward mobility. Patients with alcohol use disorder and those with schizophrenia-related disorders showed more frequent downward mobility compared to patients with mood disorder. These findings were similar to the results of previous studies $[18,19]$ whereby patients with schizophrenia have a higher risk 
for deteriorated employment status compared to those with mood disorders. Generally, among the two theories explaining the relationships between psychiatric disorder and poverty, the social causative theory is known to be suitable for depressive disorder, while the social selection and drift theory is suitable for schizophrenia [35].

The pattern of medical care utilization significantly affected the patients' downward mobility. Patients with regular use of outpatient clinic have a lower risk for downward mobility compared to patients with irregular outpatient clinic use. These findings consider that regular outpatient clinic use may prevent the deterioration of symptoms and regular users of outpatient clinics may have high compliances, thereby resulting in a lower risk of downward mobility. Regarding the type of hospital at the first admission, the risk was higher in patients who were admitted to a hospital or a clinic compared to those who were admitted to a tertiary hospital. These results suggest potential differences in the quality of interventions according to the type of hospital, and intensive and effective interventions seemed to be provided at tertiary hospitals compared to hospitals or clinics [30]. However, the severity of the disease, socioeconomic status, and family support may differ depending on the type of hospital, and it is a limitation that such elements were not included in the data analysis due to the unavailability of this data.

Intensive and effective treatment of psychiatric disorder at its onset is known to reduce long-term hospitalization [5]. However, if effective intervention is not provided at the early stage and hospitalization is prolonged, psychiatric patients may have difficulties returning to society due to social dysfunction and personality deterioration along with financial loss due to escalating medical expenses [36]. In this study, the risk of downward mobility was 8.69 times higher in patients who experienced a long-term hospitalization compared to those who did not. Because patients who experienced a long-term hospitalization have relatively high disease severity, they may have a relatively low possibility of returning to society and spend more medical expenses, which may result in downward mobility. Long-term hospitalization and the type of hospital at the first admission are seen as highly relevant variables; $25.1 \%$ of patients who were admitted to a hospital, whereas only $1.9 \%$ of patients who were admitted to a tertiary hospital experienced a long-term hospitalization. When the type of hospital at the first admission was excluded from the logistic regression analysis, the odds ratio of long-term hospitalization to down- ward mobility was greater than 8.69 times. When the total medical expense was included in the form of a continuous variable in the logistic regression analysis in order to adjust for other variables, the effects on downward mobility were not statistically significant. However, when total medical expense was included in the analysis in the form of a categorical variable, as the medical expense increased, the risk of downward mobility was higher, which was statistically significant. Therefore, the effects of medical expense on downward mobility should be carefully interpreted.

The limitations of this study are as follows. This study was conducted using the data of a previous study by Suh et al. [30]. Because variables, such as patients' socioeconomic status, severity of disease, and household characteristics were not included in that data, they were not included in this analysis. In this study, which did not include socioeconomic status highly associated with the downward mobility of psychiatric patients, analyzing factors affecting the downward mobility of psychiatric patients is limited. However, it is reasonable to examine the overall status of downward mobility from NHI beneficiaries to Medical Aid recipients among the whole first-episode psychiatric patients using this data. Although a survival analysis is considered more appropriate than a logistic regression analysis as a methodology for examining the downward mobility, a survival analysis could not be applied in this study, which used data by year. If a survival analysis is applied in further studies, the downward mobility can be examined more clearly. In this study, the risk of downward mobility was lower if the type of hospital at the first admission was a tertiary hospital or general hospital. Patients who selected such a hospital as the first at admission are likely to be in a relatively upper income bracket. Because of this, the risk of downward mobility may appear low. However, this was not verified because the $\mathrm{NHI}$ premium income quartiles were not included in this study. Further analysis is needed on the downward mobility of psychiatric patients by subdividing the $\mathrm{NHI}$ premium by income quartile. Although the hierarchical mobility of psychiatric patients three years after the onset was examined, the threeyear may be slightly short to observe downward mobility, and thus long-term follow-up studies are necessary. Due to the study limitations and the nature of this study design, a comparison of downward mobility among the general population group was not conducted. When examining the status of the National Basic Livelihood Security recipients to compare the downward mobility of general population group, 160000 to 
290000 new recipients were generated annually between 2005 and 2007 [37]. This corresponded to $0.35 \%$ to $0.60 \%$ of the total population, which was very low compared to $10.7 \%$ of the first-episode psychiatric patients who experienced downward mobility. Although the health insurance status as a hierarchical status verified by the official standards of the government was used, one weakness is that the number of Medical Aid recipients in Korea is very limited. Since the near poor are not included in Medical Aid recipients, the analysis of downward mobility of the near poor was not performed.

In this study, long-term hospitalization, type of hospital at the first admission, and regular use of outpatient care may affect the downward mobility of psychiatric patients. Intensive and effective treatment at the early stage of diagnosis is thought to prevent long-term hospitalization and downward mobility of psychiatric patients.

\section{ACKNOWLEDGEMENTS}

This study was supported by the National Human Rights Commission of Korea and the Education and Research Encouragement Fund of Seoul National University Hospital. This study was supported by "2008 Surveys on Human Rights of the Psychiatric Disabilities" project which was granted by the National Human Rights Commission of Korea.

\section{CONFLICT OF INTEREST}

The authors have no conflicts of interest associated with the material presented in this paper.

\section{ORCID}

Un-Na Kim http://orcid.org/0000-0002-6764-2951

Yeon-Yong Kim http://orcid.org/0000-0003-2179-8931

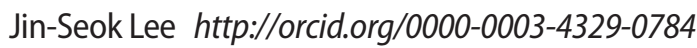

\section{REFERENCES}

1. Whiteford HA, Degenhardt L, Rehm J, Baxter AJ, Ferrari AJ, Erskine $\mathrm{HE}$, et al. Global burden of disease attributable to mental and substance use disorders: findings from the Global Burden of Disease Study 2010. Lancet 2013;382(9904):1575-1586.

2. Mathers $C D$, Loncar D. Projections of global mortality and burden of disease from 2002 to 2030. PLoS Med 2006;3(11):e442.
3. Ministry of Health and Welfare. The epidemiological survey of mental disorders among Korean adults. Seoul: Seoul National University College of Medicine; 2011, p. 12-13 (Korean).

4. Park JH, Yoon SJ, Lee HY, Cho HS, Lee JY, Eun SJ, et al. Estimating the burden of psychiatric disorder in Korea. J Prev Med Public Health 2006;39(1):39-45 (Korean).

5. McGorry PD, Killackey E, Yung AR. Early intervention in psychotic disorders: detection and treatment of the first episode and the critical early stages. Med J Aust 2007;187(7 Suppl):S8S10.

6. World Health Organization. Mental health and development: targeting people with mental health conditions as a vulnerable group [cited 2015 Dec 20]. Available from: http://www. who.int/mental_health/policy/development/mh_devel_targeting_summary_2010_en.pdf.

7. Sullivan WP. "It helps me to be a whole person": the role of spirituality among the mentally challenged. Psychosoc Rehabil J 1993;16(3): 125-134.

8. Jeong WC, Park YJ. A study on the predictor variables of employment in the persons with psychiatric disabilities. Disabil Employ 2012;22(4):187-209 (Korean).

9. Thornicroft G, Brohan E, Rose D, Sartorius N, Leese M; Indigo Study Group. Global pattern of experienced and anticipated discrimination against people with schizophrenia: a cross-sectional survey. Lancet 2009;373(9661):408-415.

10. Lund C, Breen A, Flisher AJ, Kakuma R, Corrigall J, Joska JA, et al. Poverty and common mental disorders in low and middle income countries: a systematic review. Soc Sci Med 2010;71(3): 517-528.

11. Fox JW. Social class, mental illness, and social mobility: the social selection-drift hypothesis for serious mental illness. J Health Soc Behav 1990;31(4):344-353.

12. Miech RA, Caspi A, Moffitt TE, Wright BE, Silva PA. Low socioeconomic status and mental disorders: a longitudinal study of selection and causation during young adulthood. Am J Sociol 1999;104(4):1096-1131

13. Kessler RC, Foster CL, Saunders WB, Stang PE. Social consequences of psychiatric disorders, I: educational attainment. Am J Psychiatry 1995;152(7):1026-1032.

14. Dohrenwend BP, Levav I, Shrout PE, Schwartz S, Naveh G, Link $\mathrm{BG}$, et al. Socioeconomic status and psychiatric disorders: the causation-selection issue. Science 1992;255(5047):946-952.

15. Eaton WW. A formal theory of selection for schizophrenia. AJS 1980;86(1):149-158.

16. Turner RJ, Wagenfeld MO. Occupational mobility and schizo- 
phrenia: an assessment of the social causation and social selection hypotheses. Am Sociol Rev 1967;32(1):104-113.

17. Ministry of Health and Welfare. National survey on persons with disabilities, 2014 [cited 2015 Dec 20]. Available from: http://www.mohw.go.kr/front_new/al/sal0301vw.jsp?PAR_ MENU_ID $=04 \& M E N U \_I D=0403 \& B O A R D \_I D=140 \& B O A R D$ FLAG $=00 \& C O N T \_S E Q=318756 \&$ page $=1$ (Korean).

18. Aro S, Aro H, Keskimäki I. Socio-economic mobility among patients with schizophrenia or major affective disorder. A 17-year retrospective follow-up. Br J Psychiatry 1995;166(6):759-767.

19. Wewiorski NJ, Fabian ES. Association between demographic and diagnostic factors and employment outcomes for people with psychiatric disabilities: a synthesis of recent research. Ment Health Serv Res 2004;6(1):9-21.

20. Marwaha S, Johnson S. Schizophrenia and employment: a review. Soc Psychiatry Psychiatr Epidemiol 2004;39(5):337-349.

21. Rogers ES, Anthony WA, Cohen M, Davies RR. Prediction of vocational outcome based on clinical and demographic indicators among vocationally ready clients. Community Ment Health J 1997;33(2):99-112.

22. Cook JA, Razzano L. Vocational rehabilitation for persons with schizophrenia: recent research and implications for practice. Schizophr Bull 2000;26(1):87-103.

23. Tsang HW, Leung AY, Chung RC, Bell M, Cheung WM. Review on vocational predictors: a systematic review of predictors of vocational outcomes among individuals with schizophrenia: an update since 1998. Aust N Z J Psychiatry 2010;44(6):495-504.

24. Lee SW. A study of factors on the poverty of the mentally disabled people: a panel logit approach. J Disabil Welf 2013;20(20): 89-101 (Korean).

25. Kim TW, Yoon SY, Park JH. The income mobility and income determinants of the disabled people. Soc Welf Policy 2010;37(3): 115-139 (Korean).

26. Park J, Kim J. Income mobility and poverty status of the disabled householdsz: 3rd Panel Survey of Employment for the
Disabled Conference. Seongnam: Employment Development Institute; 2011, p. 3-22 (Korean).

27. Jeon MR. A study on factors of job maintenance prediction for persons with mental disorder [dissertation]. Daegu: Daegu University; 2009 (Korean).

28. Shin HU. Occupational mobility and people with psychiatric disabilities: an assessment of the social causation and social selection hypotheses. Disabil Employ 2009;19(3):125-154 (Korean).

29. Lee HK, Lee BH. The current status and cause of the addiction problem. Health Welf Policy Forum 2013;(200):30-42 (Korean).

30. Suh SK, Kim Y, Park JI, Lee MS, Jang HS, Lee SY, et al. Medical care utilization status and associated factors with extended hospitalization of psychiatric patients in Korea. J Prev Med Public Health 2009;42(6):416-423 (Korean).

31. Lelliott P, Wing J, Clifford P. A national audit of new long-stay psychiatric patients. I: method and description of the cohort. Br J Psychiatry 1994;165(2):160-169.

32. Chung W, Chang HS, Oh SM, Yoon CW. Factors associated with long-stay status in patients with schizophrenia: an analysis of national databases covering the entire Korean population. Int J Soc Psychiatry 2013;59(3):207-216.

33. Burchardt T. Being and becoming: social exclusion and the onset of disability; 2003 [cited 2016 Jan 10]. Available from: http://sticerd.Ise.ac.uk/dps/case/CR/CASEreport21.pdf.

34. Meyer BD, Mok WK; National Bureau of Economic Research. Disability, earnings, income and consumption. Cambridge, MA: National Bureau of Economic Research; 2009, p. 3.

35. Saraceno B, Levav I, Kohn R. The public mental health significance of research on socio-economic factors in schizophrenia and major depression. World Psychiatry 2005;4(3):181-185.

36. Thornicroft G, Bebbington P, Leff J. Outcomes for long-term patients one year after discharge from a psychiatric hospital. Psychiatr Serv 2005;56(11):1416-1422.

37. Park NH. Assessment of the last 10 years of the national basic social security. Health Welf Policy Forum 2010;(167):6-13 (Korean). 